\title{
INDUÇÃO DE MULTIBROTAÇÃO IN VITRO EM VIDEIRA cV. BORDÔ ${ }^{1}$
}

\author{
RICARDO ANTONIO AYUB ${ }^{2}$, BRUNA SPINARDI ${ }^{3}$, \\ MARCOS FERNANDO BASSO ${ }^{4}$, LUIZ ANTONIO BIASI $^{5}$
}

RESUMO-A micropropagação possibilita a propagação massal e pode contribuir para atender à demanda de plantas-matrizes e mudas de qualidade genética e sanitária comprovadas de videira. Diferentes meios de cultura, acrescidos ou não de reguladores vegetais, tem sido usado com frequência para auxiliar na indução de brotações. O trabalho teve por objetivo avaliar os meios de cultura MS e GZ completo ou com metade da concentração de sais acrescidos de BAP para indução de multibrotação em videira da cv. Bordô. O experimento foi realizado em delineamento inteiramente casualizado, em esquema fatorial $4 \times 4$, com quatro meios de cultura (MS, MS/2, GZ, GZ/2) e quatro concentrações de BAP $(0 ; 2,5 ; 5$ e $10 \mu \mathrm{M})$, com quatro repetições. Avaliaram-se aos 30 dias o número de brotos por microestaca, número de novas microestacas por broto, número de folhas por broto, comprimento médio dos brotos, número de raízes por microestaca e comprimento da raiz principal. O meio de cultura mais eficiente para indução de multibrotação em videira cv. Bordô e o desenvolvimento da parte aérea é o meio MS acrescido de 2,5 $\mu \mathrm{M}$ de BAP.

Termos para indexação: Vitis labrusca, citocinina, micropropagação.

\section{INDUCTION OF MULTI-SPROUTING IN VITRO IN GRAPEVINE cv. BORDÔ}

ABSTRACT- The Micropropagation allows mass propagation and may contribute to attend the demands of mother plants and seedlings of grapevine of proved genetic quality and health. Different culture media, with or without plant growth regulators has been used frequently to assist in the induction of shoots. The study aimed to evaluate the means of culture MS and GZ full or with half the concentration of salts plus BAP for induction of multi-sprouting on grapevine $\mathrm{cv}$. Bordo. The experiment was conducted in a randomized design in a factorial $4 \times 4$, with four culture media $(\mathrm{MS}, \mathrm{MS} / 2, \mathrm{GZ}, \mathrm{GZ} / 2)$ and four concentrations of BAP $(0,2.5$, 5 and $10 \mu \mathrm{M}$ ) with four replications. It was evaluated at 30 days the number of micro-shoots per cutting, number of new micro-cuttings per shoot, number of leaves per shoot, mean length of shoots, number of roots by micro-cutting and length of the main root. The culture medium more efficient for induction of multisprouting in grapevine cv. Bordo and the development of the shoot is the MS medium plus $2.5 \mu \mathrm{M}$ of BAP. Index terms: Vitis labrusca, cytokine, micropropagation.

\section{INTRODUÇÃO}

A videira, pertencente ao gênero Vitis, da família Vitaceae, possui inúmeras espécies, destacando-se a Vitis vinifera, conhecida como produtora de uvas finas, de origem europeia, e a Vitis labrusca L., conhecida como produtora de uvas rústicas, de origem americana (ROBERTO et al., 2008; GIOVANNINI, 2008).

Conforme Regina (2006) a área cultivada com vinhedos no mundo, em 2005, foi de 7,3 milhões de hectares, com produção de 65,9 milhões de toneladas de uvas. Segundo o Anúario Brasileiro da Fruticultura (2008) o Brasil encontra-se atualmente em $22^{\circ}$ lugar, com mais de 89.946 hectares, com produção de 1.354 .960 toneladas, $15^{\circ}$ lugar em produção de vinhos e $8^{\circ}$ maior exportador de suco de uva.

A viticultura no Brasil está concentrada principalmente nos Estados das regiões Sul e Sudeste, onde se destacam os dois maiores produtores nacionais: Rio Grande do Sul, com 48.474 hectares e produção de 705.228 toneladas sendo $90 \%$ da produção destinada a agroindústria para produção de vinhos, suco e outros derivados e São Paulo, com

\footnotetext{
1(Trabalho 155-09). Recebido em: 22-06-2009. Aceito para publicação em: 27-04-2010.

${ }^{2}$ Prof. PhD. Universidade Estadual de Ponta Grossa - UEPG, Departamento de Fitotecnia e Fitossanidade, Av. Carlos Cavalcante, 4748, 84030-900 - Ponta Grossa-PR, Brasil, Bolsista da Fundação Araucária. Autor para contato: rayub@uepg.br

${ }^{3}$ Graduanda em Ciências Biológicas pela Universidade Estadual de Ponta Grossa - UEPG, Departamento de Fitotecnia e Fitossanidade, Av. Carlos Cavalcante, 4748, 84030-900 - Ponta Grossa-PR, Brasil, email: bruspin@hotmail.com

${ }^{4}$ Biotecnólogo, Mestrando em Agronomia, bolsista da Fundação Araucária, Universidade Estadual de Ponta Grossa - UEPG, Departamento de Fitotecnia e Fitossanidade, Av. Carlos Cavalcante, 4748, 84030-900 - Ponta Grossa-PR, Brasil, email: marcosbiotec@gmail.com.

${ }^{5}$ Prof. Dr. Universidade Federal do Paraná - UFPR, Departamento de Fitotecnia e Fitossanitarismo. Curitiba-PR. Bolsista de Produtividade em Pesquisa do CNPq, email: biasi@ufpr.br
} 
12.303 hectares de área colhida e produção prevista de 231.620 toneladas de uva. Do total de uvas produzidas no Brasil, em 2007, 47,02\% foi destinada à elaboração de vinhos, sucos e outros derivados (EMBRAPA UVA E VINHO, 2007; ANTUNES; AQUINO, 2008; AGRIANUAL, 2006).

A videira cv. Bordô, na década de 1850, despertou interesse dos viticultores europeus devido à resistência ao oídio (Uncinula necator), moléstia que naquela época causava enorme prejuízo à viticultura mundial (GRIGOLETTI JR.; SONEGO, 1993). Foi introduzida no Rio Grande do Sul, em 1839, com o nome de 'Ives'. Sua expansão deu-se devido à fácil adaptação à variabilidade de condições edafoclimáticas, boa produtividade (aprox. 32.000 t.ha $^{-1}$ ), longevidade e relativa rusticidade (ZANUZ, 1991; CAMARGO, 1994), sendo bastante utilizada para elaboração de vinho tinto, suco, vinagre, geleias e, por sua precocidade, também consumida in natura (RIZZON et al., 2000).

A micropropagação da videira é utilizada com diversos objetivos, entre os quais a multiplicação rápida de plantas, propagação de novos híbridos e obtenção de matrizes livres de patógenos, tornandose uma alternativa viável para a multiplicação de videiras (BIASI et al., 1998a; DZAZIO et al., 2002; COLETTO et al., 2008).

Para induzir o crescimento dos explantes in vitro, recomenda-se a adição de uma citocinina ao meio de cultura inicial (BOUQUET; TORREGROSA, 2003; MACHADO et al., 2006), sendo a 6-benzilaminopurina (BAP) a mais utilizada e a mais efetiva para um grande número de cultivares (BIASI et al., 1998a; NOVÁK; JUVOVÁ, 1983; GRAY;BENTON, 1990).

As citocininas são utilizadas para estimular a divisão celular, atuando desta forma na morfogênese (GEORGE, 1996). A concentração e o tipo de citocinina, para a melhor proliferação de brotações, podem variar entre os diferentes genótipos (DZAZIO et al., 2002); contudo, as concentrações muito elevadas também são prejudiciais, causando a formação de brotações anormais e hiper-hídricas (MACHADO et al., 2006).

Desde a década de 80, a técnica de micropropagação in vitro tem sido uma alternativa utilizada para superar as dificuldades de propagação dessa espécie, mas foi somente a partir de 1990 que se conseguiu obter o primeiro enraizamento in vitro (LEE; WETZSTEIN, 1990). No caso da videira, as técnicas de cultivo in vitro têm demonstrado grande potencial para a propagação de plantas (TORREGROSA; BOUQUET, 1995; TORREGROSA et al., 1995; SILVA et al., 1997; BIASI et al., 1998b).
Para Novák e Juvová (1983), a citocinina BAP mostrou-se mais eficiente até mesmo que a cinetina e a 2 -isopenteniladenina (2ip), para estimular o crescimento de meristemas e a proliferação de novas brotações, em oito clones de videira.

De forma geral, quase todos os trabalhos apontam, como melhor meio de cultura para a produção de brotos, o meio MS completo (LEE; WETZSTEIN, 1990), ou modificado com metade da concentração de sais (SUDARSONO et al., 1991). Para Bernd et al. (2007), o regulador vegetal BAP apresentou os melhores resultados na produção de brotos, em concentrações variáveis e específicas, para cada variedade ou híbrido em estudo. Ainda o mesmo autor verificou que o meio GZ, acrescido de $3 \mu \mathrm{M}$ de BAP, também foi eficiente na indução de multibrotação em porta-enxertos híbridos de Vitis labrusca x Vitis rotundifolia.

O presente trabalho teve por objetivo avaliar os meios MS e GZ completos ou com metade da concentração de sais acrescidos de BAP (Benzilaminopurina) com concentrações de $0 ; 2,5 ; 5,0$ e 10 $\mu \mathrm{M}$ para indução de multibrotação em videira da cv. Bordô.

\section{MATERIAL E MÉTODOS}

Os explantes utilizados na multibrotação foram segmentos nodais da cultivar Bordô, com uma gema axilar e uma folha, de aproximadamente $1 \mathrm{~cm}$ de comprimento, excisados de plantas preestabelecidas in vitro. Os explantes foram introduzidos em frascos de vidro com capacidade de $100 \mathrm{~mL}$, e tampados, contendo $20 \mathrm{~mL}$ de meio de cultura.

Os meios de cultura utilizados foram o MS (MURASHIGE; SKOOG, 1962) completo ou com metade da concentração de sais, acrescidos de 6 g.L.-1 de ágar, 30 g.L $L^{-1}$ de sacarose e o meio GZ (GALZY et al., 1990) completo ou com metade da concentração de sais, acrescidos de 6 g.L $\mathrm{L}^{-1}$ de ágar, 15 g.L $\mathrm{L}^{-1}$ de sacarose, ambos suplementados com: $0 ; 2,5 ; 5$ e $10 \mu \mathrm{M}$ de BAP.

$\mathrm{O} \mathrm{pH}$ dos meios de cultura MS e MS/2 foram ajustados para $5,8 \mathrm{com} \mathrm{NaOH} 0,1 \mathrm{~N}$, e o $\mathrm{pH}$ dos meios $\mathrm{GZ}$ e GZ/2 foram ajustados para $6,5 \mathrm{com} \mathrm{NaOH}$ $0,1 \mathrm{~N}$ após a adição de agar; em seguida, os meios foram esterilizados em autoclave a $120^{\circ} \mathrm{C}$, durante 20 minutos

Os experimentos foram mantidos dentro de uma sala climatizada, com fotoperíodo de 16 horas de luz, fornecidas por lâmpadas fluorescentes do tipo luz do dia, intensidade luminosa de aproximadamente $20 \mu \mathrm{mol} \mathrm{m}{ }^{-2} \mathrm{~s}^{-1} \mathrm{e}$ temperatura de $25 \pm 1^{\circ} \mathrm{C}$.

$\mathrm{O}$ experimento foi realizado em delineamento inteiramente casualizado, em esquema fatorial 4 x 4, 
com quatro meios de cultura (MS, MS/2, GZ e GZ/2) e quatro concentrações de $\operatorname{BAP}(0 ; 2,5 ; 5$ e $10 \mu \mathrm{M})$, com quatro repetições. A unidade experimental foi constituída de 4 frascos contendo 4 explantes cada frasco.

As avaliações foram realizadas 30 dias a partir da instalação do experimento, e os parâmetros observados foram: número de brotos por microestaca, número de novas micro-estacas por broto, número de folhas por broto, comprimento médio dos brotos, número de raízes por microestaca e comprimento da raiz principal.

\section{RESULTADOS E DISCUSSÃO}

Para todos os parâmetros avaliados, houve interação significativa entre os meios de cultura e as concentrações de BAP testadas. Os maiores valores de número de brotos por microestaca foram obtidos no meio MS/2 com $5 \mu \mathrm{M}$ de BAP, embora esse meio não tenha diferido estatisticamente dos meios MS com 2,5; 5 e $10 \mu \mathrm{M}$ de BAP e GZ e GZ/2 com 2,5 e 5 $\mu$ Mde BAP (Tabela 1). Chée e Pool (1985) já haviam observado maior produção de brotos na concentração de 2,5 $\mu \mathrm{M}$ de BAP para o híbrido 'Remaily Seedless'.

Já Coletto et al. (2008) observaram, na micropropagação do porta-enxerto Paulsen 1103, que o meio MS, acrescido de 2,5 $\mu \mathrm{M}$ de BAP, apresentou brotações com maior tamanho e, na concentração de $1 \mu \mathrm{M}$ de BAP, apresentou número maior de brotações, embora as concentrações com 0; 0,5 e 2,5 $\mu \mathrm{M}$ de BAP não tenham diferido estatisticamente. Para o porta-enxerto '420-A', Dzazio et al. (2002) observaram que o meio de cultura contendo BAP de 1 a $10 \mu \mathrm{M}$ não apresentou diferenças estatísticas significativas no número de brotações. Machado et al. (2006), trabalhando com o porta-enxerto 'VR043-43', observaram que as concentrações com 5 e $10 \mu \mathrm{M}$ de BAP, com subcultivos a cada 45 dias, promoveram o maior número de brotações, porém com redução da altura. Para Torregrosa e Bouquet (1995), o meio de cultura MS/2, suplementado com $4,4 \mu \mathrm{M}$ de BAP, promoveu alto número de brotações por explantes, para os híbridos de Vitis x Muscadinia. Nos trabalhos de Gray e Benton (1991), o número e a qualidade das brotações das cultivares de videiras Fry, Carlos e Dixie foram altos quando o meio foi suplementado com 5 a $20 \mu \mathrm{M}$ BAP, diferentemente deste trabalho, onde a concentração de BAP acima de $5 \mu \mathrm{M}$ apresentou redução no número de brotos.

Bernd et al. (2007) induziram multibrotação a partir de gemas axilares de híbridos $V$. labrusca x $V$. rotundifolia com um número satisfatório de brotos, passível de ser incrementado por subcultivos sucessivos, em meio Galzy, acrescido de $3 \mu \mathrm{M}$ de bezilaminopurina (BAP), os maiores números de brotos foram obtidos em meio Galzy, porém, em meio MS houve melhor desenvolvimento da parte aérea, com caule levemente mais grosso e vigoroso, que resultou em melhor enraizamento, com raízes mais grossas e mais ramificadas.

Lee e Wetzstein (1990) observaram em Vitis rotundifolia, cv. Summit que em meio MS, acrescido de $10 \mu \mathrm{M}$, induziu maior número de brotos, já na concentração de $5 \mu \mathrm{M}$, obtiveram melhor enraizamento, com raízes maiores e mais ramificadas.

Biasi et al. (1998b), conseguiram o máximo estímulo de desenvolvimento dos ápices meristemáticos utilizando meio MS com metade da concentração de sais, acrescidos de 7,4 $\mu \mathrm{M}$ e $7,8 \mu \mathrm{M}$ de BAP, para os porta-enxertos 'Jales' e 'Campinas', respectivamente. Bernd et al. (2007), trabalhando com dois híbridos de Vitis labrusca x V. rotundifolia, obtiveram maior número de brotos utilizando meio de cultura GZ, acrescido de 3 e $5 \mu \mathrm{M}$ de BAP.

Concordando com Biasi et al. (1998a) Dzazio et al. (2002) e Lee e Wetzstein (1990), concentrações de BAP devem ser adequadas para cada cultivar, otimizando o processo para a obtenção de brotações de boa qualidade e com mínimo de vitrificação, mesmo que a taxa de crescimento seja menor.

Em relação ao número de novas microestacas formadas por broto (Tabela 1), o meio MS, acrescido de 2,5 $\mu \mathrm{M}$ de BAP, foi o que apresentou maior número de novas microestacas formadas por broto originado. Já para os meios MS/2 e GZ/2, a concentração de $2,5 \mu \mathrm{M}$ de BAP não diferiu das testemunhas, sendo a mesma superior ao meio GZ.

Biasi et al. (1998b), conseguiram a melhor resposta no número de explantes com folhas, utilizando $10 \mu \mathrm{M}$ de BAP com os porta-enxertos 'Jales' e 'Campinas'. Ainda os mesmos autores, verificaram que o aumento da concentração de BAP até no máximo com $11,5 \mu \mathrm{M}$ de BAP induziu o crescimento das gemas axilares dos segmentos nodais, e concentrações muito elevadas de BAP causaram brotações anormais. Gray e Benton (1991), utilizando meio de cultura acrescido de 5 a $20 \mu \mathrm{M}$ de BAP, obtiveram alto número e qualidade das brotações nas cultivares Fry, Carlos e Dixie.

Avaliando o número de folhas por microestaca de videira, constatou-se que o meio MS, acrescido de 2,5 $\mu \mathrm{M}$ de BAP, foi o que apresentou o maior número de folhas em relação aos outros meios de cultura, na mesma concentração de BAP, enquanto nos meios GZ e GZ/2 não houve diferença entre as concentrações de BAP (Tabela 1). Dzazio et al. (2002), na micropropagação do porta-enxerto 
de videira '420-A', encontraram maior número de folhas nos tratamento com ausência de BAP e na concentração de $1 \mu \mathrm{M}$ de BAP e também observaram que concentrações muito altas diminuíram a quantidade de folhas, afetando seu desenvolvimento e a qualidade das brotações.

Bernd et al. (2007), trabalhando com dois híbridos de Vitis labrusca $\mathrm{x}$ V. rotundifolia observaram que o meio de cultura MS, acrescido de 5 $\mu \mathrm{M}$ de BAP, apresentaram melhor desenvolvimento da parte aérea, com caule levemente mais grosso e vigoroso. Machado et al. (2006), trabalhando com o porta-enxerto 'VR043-43', observaram que a citocinina BAP apresentou resultados inferiores à testemunha, no primeiro subcultivo e nos cultivos posteriores, o número de folhas por brotação aumentou, contudo os valores foram próximos ao da testemunha.

Dzazio et al. (2002) observaram maior número de folhas nos tratamentos com meio de cultura MS e MS/2 na ausência de BAP e na concentração de $1 \mu \mathrm{M}$, sendo que, nas concentrações mais altas, diminuíram a quantidade de folhas, afetando seu desenvolvimento e a qualidade das brotações, que apresentaram sintomas de vitrificação.

Em relação ao comprimento médio dos brotos e ao número de raízes, o meio $\mathrm{MS} / 2$, sem a adição de BAP, foi o que apresentou o melhor resultado (Tabela 2), sem diferir do meio MS e GZ. O meio $\mathrm{GZ} / 2$ foi o que apresentou o menor comprimento dos brotos. Isto se deve ao fato de a citocinina presente nos demais tratamentos ser prejudicial ao desenvolvimento da parte aérea. Isto é importante, pois além do maior número de brotos, o comprimento deles pode permitir aumento no número de estacas obtidas para a propagação da videira cv. Bordô.

Machado et al. (2006), trabalhando com o porta-enxerto 'VR043-43', verificaram, quando o meio de cultura foi acrescido de 5 ou $10 \mu \mathrm{M}$ de BAP, com subcultivos a cada 45 dias, efeito negativo na altura das brotações. Ainda os mesmos autores, observaram que a cinetina também apresentou efeito negativo na altura das brotações quando o meio de cultura foi acrescido de 5 e $10 \mu \mathrm{M}$.

Mahtre et al. (2000) ainda observaram produção de brotações poucas alongadas quando o meio de cultura foi acrescido de BAP nas cultivares Thompson Seedless, Sonaka e Tas-e-Ganesh. Koruza e Jelaska (1993) também observaram inibição no crescimento das brotações de videira, na subcultura repetida em meio de cultura, acrescido de citocinina. Coletto et al. (2008) verificaram que o meio MS/2, acrescido de 1 ou 2,5 $\mu \mathrm{M}$ de BAP, apresentou melhor resultado no comprimento dos brotos no porta- enxerto 'Paulsen 1103 ' e quando acrescido de $5 \mu \mathrm{M}$, ocorreu um efeito tóxico, reduzindo o crescimento dos porta-enxertos.

Dzazio et al. (2002) obtiveram maior comprimento da brotação principal da gema axilar utilizando o meio de cultura MS com a concentração normal de sais, embora se verificou a tendência dos efeitos do $\mathrm{MS}$ normal e MS/2 se igualarem à medida que foram realizados os subcultivos. Já, o MS/4 apresentou redução no crescimento das brotações no primeiro subcultivo, realizado após os 30 dias no meio de indução com presença de BAP. Para Gray e Klein (1989) o meio de cultura MS normal também foi superior no desenvolvimento de meristemas apicais da cultivar Blanc Du Bois.

Como era de se esperar o número e o comprimento de raízes foram maiores no meio $\mathrm{MS} / 2 \mathrm{sem}$ hormônios, apesar de não diferir dos outros tratamentos também sem a adição de hormônio, o que comprova o efeito negativo das citocininas no enraizamento (Tabela 2). Ao contrario de Bernd et al. (2007) e Lee e Wetzstein (1990) onde o melhor enraizamento foi verificado no meio MS com $5 \mu \mathrm{M}$ de BAP.

Torregrosa e Bouquet (1995), estudando diferentes híbridos de $V$. rotundifolia, observaram que o meio $\mathrm{MS} / 2$, acrescido de 4,4 $\mu \mathrm{M}$ de BAP, apresentou os melhores índices de multibrotação, mas reduziu o enraizamento quando comparada à concentração de 1,1 $\mu \mathrm{M}$ de BAP. Machado et al. (2006) verificaram que a adição de BAP no meio de cultura reduziram a formação de raízes, inibindo totalmente o enraizamento no terceiro subcultivo, contudo a cinetina não inibiu o enraizamento das microestacas, apenas a concentração de $10 \mu \mathrm{M}$ no quarto subcultivo, reduziu significativamente a porcentagem de enraizamento $(65,8 \%)$.

Dzazio et al. (2002) obtiveram porcentagem média de enraizamento para os tratamentos com meios de cultura MS/2 e MS/2 mais carvão ativado, considerada alta, com $80 \%$ dos segmentos nodais apresentando raízes. Biasi et al. (1998b), também trabalhando com segmentos nodais, obtiveram, para o porta-enxerto 'Jales', taxas de enraizamento próximas de $100 \%$, no meio MS/2 sem auxina. 
TABELA 1 - Número de brotos emitidos por microestaca, número de novas microestacas formadas por broto e número de folhas por broto de videira cv. Bordô, após 30 dias de cultivo in vitro, em diferentes meios de cultura, com diferentes concentrações de BAP. Ponta Grossa-PR. 2008.

\begin{tabular}{|c|c|c|c|c|}
\hline \multirow{2}{*}{$\begin{array}{c}\text { Concentração de BAP } \\
(\mu \mathrm{M})\end{array}$} & \multicolumn{4}{|c|}{ Número de brotos } \\
\hline & $\mathrm{MS} / 2$ & MS & GZ & $\mathrm{GZ} / 2$ \\
\hline 0 & $1,1 \mathrm{Ba}$ & $0,8 \mathrm{Ba}$ & $1,1 \mathrm{Ba}$ & $1,0 \mathrm{BCa}$ \\
\hline 2,5 & $1,7 \mathrm{Ba}$ & $2,2 \mathrm{Aa}$ & $2,0 \mathrm{ABa}$ & $2,1 \mathrm{Aa}$ \\
\hline 5 & 2,9 Aa & 2,3 Aab & 2,5 Aab & $1,8 \mathrm{ABb}$ \\
\hline 10 & 1,9 Bab & $2,1 \mathrm{Aa}$ & $1,1 \mathrm{Bbc}$ & $0,7 \mathrm{Cc}$ \\
\hline \multirow[t]{2}{*}{$\mathrm{CV}(\%)$} & \multicolumn{4}{|c|}{29,16} \\
\hline & \multicolumn{4}{|c|}{ Número de novas microestacas } \\
\hline 0 & $2,7 \mathrm{Aa}$ & $1,9 \mathrm{Bb}$ & $2,1 \mathrm{Aab}$ & $1,5 \mathrm{Ab}$ \\
\hline 2,5 & $2,3 \mathrm{Ab}$ & $3,2 \mathrm{Aa}$ & $1,0 \mathrm{Bc}$ & $1,3 \mathrm{Ac}$ \\
\hline 5 & $1,4 \mathrm{Ba}$ & $1,8 \mathrm{BCa}$ & $1,1 \mathrm{Ba}$ & $1,4 \mathrm{Aa}$ \\
\hline 10 & $1,0 \mathrm{Ba}$ & $1,2 \mathrm{Ca}$ & $0,8 \mathrm{Ba}$ & $0,5 \mathrm{Ba}$ \\
\hline CV $(\%)$ & \multicolumn{4}{|c|}{24,52} \\
\hline & \multicolumn{4}{|c|}{ Número de folhas } \\
\hline 0 & $4,1 \mathrm{Aa}$ & $3,4 \mathrm{Ba}$ & 4,0Aa & 3,9Aa \\
\hline 2,5 & $4,6 \mathrm{Ab}$ & $10,2 \mathrm{Aa}$ & $4,6 \mathrm{Ab}$ & $4,9 \mathrm{Ab}$ \\
\hline 5 & $5,5 \mathrm{Aa}$ & $7,5 \mathrm{Aa}$ & $5,1 \mathrm{Aa}$ & $4,2 \mathrm{Aa}$ \\
\hline 10 & $3,5 \mathrm{Aab}$ & $7,3 \mathrm{ABa}$ & $2,0 \mathrm{Ab}$ & $1,1 \mathrm{Ab}$ \\
\hline CV (\%) & \multicolumn{4}{|c|}{43,84} \\
\hline
\end{tabular}

* As médias seguidas de mesma letra maiúscula na coluna e minúscula na linha não diferem entre si, pelo teste de Tukey $(\mathrm{P} \leq 0,05)$.

TABELA 2 - Comprimento médio dos brotos, número de raízes por microestaca, comprimento da raiz principal de videira cv. Bordô, após 30 dias de cultivo in vitro, em diferentes meio de cultura e diferentes concentrações de BAP. Ponta Grossa-PR. 2008.

\begin{tabular}{|c|c|c|c|c|}
\hline \multirow{2}{*}{$\begin{array}{c}\text { Concentração de BAP } \\
(\mu \mathrm{M})\end{array}$} & \multicolumn{4}{|c|}{ Comprimento médio dos brotos } \\
\hline & $\mathrm{MS} / 2$ & MS & $\mathrm{GZ}$ & $\mathrm{GZ} / 2$ \\
\hline 0 & $1,7 \mathrm{Aa}$ & $1,5 \mathrm{Aa}$ & $1,3 \mathrm{Aa}$ & $0,5 \mathrm{Ab}$ \\
\hline 2,5 & $0,6 \mathrm{Bb}$ & $1,4 \mathrm{ABa}$ & $0,4 \mathrm{Bb}$ & $0,4 \mathrm{Ab}$ \\
\hline 5 & $0,7 \mathrm{Bab}$ & $1,0 \mathrm{ABa}$ & $0,4 \mathrm{Bb}$ & $0,6 \mathrm{Aab}$ \\
\hline 10 & $0,5 \mathrm{Ba}$ & $0,8 \mathrm{Ba}$ & $0,3 \mathrm{Ba}$ & $0,2 \mathrm{Aa}$ \\
\hline $\mathrm{CV}(\%)$ & \multicolumn{4}{|c|}{37,69} \\
\hline & \multicolumn{4}{|c|}{ Número de raízes por microestaca } \\
\hline 0 & $2,3 \mathrm{Aa}$ & $2,1 \mathrm{Aab}$ & $1,5 \mathrm{Ab}$ & $0,1 \mathrm{Ac}$ \\
\hline 2,5 & $0,2 \mathrm{Ba}$ & $0,3 \mathrm{Ba}$ & $0,0 \mathrm{Ba}$ & $0,0 \mathrm{Aa}$ \\
\hline 5 & $0,1 \mathrm{Ba}$ & $0,0 \mathrm{Ba}$ & $0,0 \mathrm{Ba}$ & $0,0 \mathrm{Aa}$ \\
\hline 10 & $0,0 \mathrm{Ba}$ & $0,1 \mathrm{Ba}$ & $0,0 \mathrm{Ba}$ & $0,0 \mathrm{Aa}$ \\
\hline CV (\%) & \multicolumn{4}{|c|}{74,89} \\
\hline & \multicolumn{4}{|c|}{ Comprimento da raiz principal } \\
\hline 0 & $6,7 \mathrm{Aa}$ & $4,0 \mathrm{Ab}$ & $5,0 \mathrm{Aab}$ & $6,4 \mathrm{Ac}$ \\
\hline 2,5 & $0,5 \mathrm{Ba}$ & $1,5 \mathrm{Ba}$ & $0,0 \mathrm{Ba}$ & $0,0 \mathrm{Ba}$ \\
\hline 5 & $0,0 \mathrm{Ba}$ & $0,0 \mathrm{Ba}$ & $0,0 \mathrm{Ba}$ & $0,0 \mathrm{Ba}$ \\
\hline 10 & $0,0 \mathrm{Ba}$ & $0,0 \mathrm{Ba}$ & $0,5 \mathrm{Ba}$ & $0,0 \mathrm{Ba}$ \\
\hline $\mathrm{CV}(\%)$ & \multicolumn{4}{|c|}{37,69} \\
\hline
\end{tabular}

* As médias seguidas de mesma letra maiúscula na coluna e minúscula na linha não diferem entre si, pelo teste de Tukey $(\mathrm{P} \leq 0,05)$. 


\section{CONCLUSÃO}

A indução de multibrotação in vitro da videira cv. Bordô pode ser realizada em meio de cultura MS, acrescido de 2,5 $\mu \mathrm{M}$ de BAP.

\section{AGRADECIMENTOS}

Ao Conselho Nacional de Desenvolvimento Científico e Tecnológico - CNPq, CAPES e à Fundação Araucária, pelo apoio financeiro.

\section{REFERÊNCIAS}

AGRIANUAL: anuário da agricultura brasileira São Paulo: Instituto FNP Consultoria e Comércio, 2006. 504p.

ANTUNES, C.E.; AQUINO, D.T. Vitivinicultura e vinhos artesanais no Estado de São Paulo. In: CORRÊA, L.S.; BOLIANI, A.C.; FRACARO, A.A. (Ed.). Uvas rústicas: cultivo e processamento em regiões tropicais. Jales: Editora Gráfica Universitária, 2008. p. 354-368.

BERND, R.B.; TRIVILIN, A.P; CAMARGO, U.A.; CZERMAINSKI, A.B.C. Micropropagação de portaenxertos híbridos de Vitis labrusca $\mathrm{x}$ Vitis rotundifolia com resistência à pérola-da-terra (Eurhizococcus brasiliensis hempel, hemiptera: margarodidae). Revista Brasileira de Fruticultura, Jaboticabal, v. 29 , n. 2, p. 350-354, 2007.

BIASI, L. A.; PASSOS, I.R. da S.; POMMER, C.V. Estabelecimento in vitro de porta-enxertos de videira através de ápices meristemáticos e segmentos nodais. Scientia Agrícola, Piracicaba, v. 55, n. 2, p. 45-49, 1998a.

BIASI, L.A.; PASSOS, I.R.S.; POMMER, C.V. Micropropagação do porta-enxerto de videira Jales. Pesquisa Agropecuária Brasileira, Brasília, v.33, n.10, p. 1587-1594, 1998b.

BOUQUET, A.; TORREGROSA, L. Micropropagation of the grapevine (Vitis spp.). In: JAIN, S. M. (Ed.). Micropropagation of woody trees and fruits. Dordrecht: Kluwer Academic, 2003. p.319-352.

CAMARGO, U.A. Uvas do Brasil. Brasília: Empresa Brasileira de Pesquisa Agropecuária, Uva e Vinho , 1994. 90 p. (Documentos, 9)
CHEÉ, R.; POOL, R.M. In vitro propagation of Vitis: the effects of organic substances on shoot multiplication. Vitis, Siebeldingen, v.24, p. 106-118, 1985.

COLETTO, L.S.; MARTINS, C.R.; GOULART, M Micropropagation of stock for grafting of grapevine Paulsen 1103 "in vitro", with different citocinina concentrations. Revista da FZVA, Uruguaiana, v.15, n.1, p. 102-108, 2008

CORRÊA, S. Anuário brasileiro de fruticultura: panorama. Santa Cruz do Sul: Editora Gazeta, 2008. $136 \mathrm{p}$.

DZAZIO, P.M.; BIASI, L.A.; ZANETTE, F. Micropropagação do porta-enxerto de videira 420-A Revista Brasileira de Fruticultura, Jaboticabal, v.24, n.3, p. 759-764, 2002

EMBRAPA Uva e Vinho. Vitivinicultura brasileira Panorama 2007. (Comunicado Técnico).

GALZY, R.; HAFFNER, V.; COMPAN, D. Influence of three factors on the growth and nutrition of grapevine microcuttings. Journal of Experimental Botany, Oxford, v.41, n. 224, p 295-301, 1990.

GEORGE, E.F. Plant propagation by tissue culture: the technology. 2.ed. Edington: Exegetics, 1.574 p., 1996.

GIOVANNINI, E. Produção de uvas para vinho, suco e mesa. 3.ed. Porto Alegre: Renascença, 2008. 368 p.

GRAY, D.J.; BENTON, C.M. In vitro micropropagation and plant establishment of muscadine grape cultivars (Vitis rotundifolia). Plant Cell, Tissue Organ Culture, Hague, v. 27, n. 1, p. 7-14, 1991.

GRAY, D.J.; BENTON, C.M. Micropropagation and plant establishment of muscadine grape. Proceedings of the Florida State Horticultural Society, Winter Haven, v. 103, p. 300-302, 1990.

GRAY, D.J.; KLEIN, L.M. In vitro micropropagation and plant establishment of 'Blanc du Bois' grapes. Proceedings of the Florida State Horticultural Society, Winter Haven, v. 102, p. 221-223, 1989. 
GRIGOLETTI Jr., A.; SÔNEGO, O.R. Principais doenças fúngicas da videira no Brasil. Bento Gonçalves: EMBRAPA CNPUV, 1993. 36p. (Circular Técnica, 17)

KORUZA, B.; JELASKA, S. Influence of meristem culture and virus elimination on phenotypical modifications of grapevine (Vitis viniferas L., cv. Refosk). Vitis, Siebeldingen, v. 32, n. 1, p. 59-60, 1993.

LEE, N.; WETZSTEIN, H.Y. In vitro propagation of muscadine grape by axillary shoot proliferation.

Journal of the American Society for Horticultural Science, Mont Vernon, v. 115, n. 2, p. 324-329, 1990.

MACHADO, M.P.; BIASI, L.A.; RITTER, M.; RIBAS, L.L.F.; KOEHLER, H.S. Multiplicação in vitro do porta-enxerto de videira VR 043-43 (Vitis vinifera $\mathrm{x}$ Vitis rotundifolia). Ciência e Agrotecnologia, Lavras, v. 30, n. 4, p. 648-655, 2006.

MHATRE, M.; SALUNKHE, C. K.; RAO, P. S. Micropropagation of Vitis vinifera L: towards an improved protocol. Scientia Horticulturae, Amsterdam, v. 84, p. 357-363, 2000.

MURASHIGE, T.; SKOOG, F.A. A revised medium for rapid growth and bio assaya with tobacco tissue cultures. Physiologia Plantarum, Copenhague, v.15, p. 473-479, 1962.

NOVÁK, F.J.; JUVOVÁ, Z. Clonal propagation of grapevine through in vitro axillary bud culture. Scientia Horticulturae, Amsterdam, v.18, n.3, p.231-240, 1983.

REGINA, M.A. Viticultura. Revista Brasileira de Fruticultura, Jaboticabal, v.28, n.2, p.160-338, 2006.
RIZZON, L. A.; MIELE, A.; MENEGUZZO, J. Avaliação da uva cv. Bordô para a elaboração de vinho tinto. Ciência e Tecnologia de Alimentos, Campinas, v.20, n.1, p.115-121, 2000.

ROBERTO, S.R.; PEREIRA, F.M.; BOLIANI, A.C.; DA SILVA, A.C.C. Origem, botânica e biologia da videira. In: CORREA L.S.; BOLIANI, A.C.; FRACARO, A.A. (Ed.). Uvas rústicas: cultivo e processamento em regiões tropicais. Jales: Editora Gráfica Universitária, 2008. p.30-50.

SILVA, A. L. da; SCHUCK, E.; HARISCAINLAFITTE, P.; PARIZZOTTO, A. Cultura in vitro do porta-enxerto de videira var. 043-43 resistente à fusariose. In: SIMPÓSIO BRASILEIRO DE MELHORAMENTO DE FRUTÍFERAS, 1., 1997, Jaboticabal. Anais... Jaboticabal: Unesp, 1997. p.51-53.

SUDARSONO, A.; GOLDY, R.G. Growth regulator and axillary bud position effects on in vitro establishment of Vitis rotundifolia. HortScience, Alexandria, v.26, n.3, p.304-307, 1991.

TORREGROSA, L.; BOUQUET, A. In vitro propagation of Vitis X Muscadinia hybrids by microcuttings o axillary budding. Vitis, Siebeldingen, v. 34, n. 2, p. 125-126, 1995.

TORREGROSA, L.; TORRES-VIÑALS, M.; BOUQUET, A. Somatic embryogenesis from leaves of Vitis x Muscadinea hybrids. Vitis, Siebeldingen, v. 34, p. 239-240, 1995.

ZANUZ, M.C. Efeito da maturação sobre a composição do mosto e qualidade do suco de uva. 1991. 117 f. Dissertação (Mestrado em Agronomia) - Faculdade de Agronomia, Universidade Federal do Rio Grande do Sul, Porto Alegre, 1991. 